\title{
Experimental Investigation of Magnetic Fuel Conditioner (M.F.C) in I.C. engine
}

\author{
Shweta Jain ${ }^{1}$, Prof. Dr. Suhas Deshmukh ${ }^{2}$ \\ ${ }^{I}$ (Singhad Academy of Engineering, Pune) \\ ${ }_{2}^{2}$ (Department of Mechanical Engineering, Singhad Academy of Engineering, Pune)
}

\begin{abstract}
Vehicle on road produces large amount of CO, HC and NOx etc. as a exhaust emission. Typically I.C. engine used in automobiles have a problem of pollutant emission, which mainly depends on combustion process occurs in I.C. engines. Incomplete combustion produces large amount of emission gases \& gives lower efficiency. To tackle these issues new way of fuel conditioner are developed called as Magnetic Fuel Conditioner (MFC). The present article describes the mechanism of MFC, objectives \& the parameter which affects the efficiency of MFC. Further, in this report one case study is presented in which ferrite magnets are used as MFC which improves efficiency and emission. A permanent magnet mounted in path of fuel lines. Mounting magnets in fuel line enhance fuel properties such as it aligns \& orients, hydrocarbon molecules, better atomization of fuel (Proper mixing of air with fuel) etc. Use of such fuel conditioners improves mileage \& better emission of vehicle. Finally this article also review about new emerging technology i.e. fuel conditioners, developments done across the globe.
\end{abstract}

Keywords: Magnetic Fuel Conditioners, Emission, Mileage, Efficiency

\section{INTRODUCTION}

Over the last decades in India, there has been a tremendous increase in number of automobiles industries. Currently, the motor vehicle population in India is about 80 million. Even though the transport sector plays pivotal role in the economic development of any country, it brings an unavoidable specter of environmental deterioration along with transportation [1]. This creates a huge problem for developing country like India. Combustion of fossil fuel in mobile sources for transportation has led to widespread release of pollutants such as $\mathrm{CO}, \mathrm{HC}$, NOx, SPM and many other harmful compounds in the environment, which results in air quality deterioration and health effects especially in urbanized areas[1,2,3]. Hence, an integrated approach for reducing emissions from mobile sources is the most desirable in urban transportations and also availability of fuel will no longer meet the growing demand.

Today's hydrocarbon fuels leave a natural deposit of carbon residue that clogs stalling, loss of horsepower and greatly decreased mileage on cars are very noticeable [6]. The same is true of home heaing units where improper combustion wasted fuel (gas) and cost, money in poor efficiency and repairs due to build-up. Most fuels for internal combustion engine are liquid, fuels do not combust until they are vaporized and mixed with air. Most emission motor vehicle consists of unburned hydrocarbons, carbon monoxide and oxides of nitrogen. Unburned hydrocarbon and oxides of nitrogen react in the atmosphere and create smog. Smog is prime cause of eye and throat irritation, noxious smell, plat damage and decreased visibility. Oxides of nitrogen are also toxic. Even when fuel is still clear and bright, microscopic fuel components agglomerate forming larger clusters and organic compounds. (i.e. chaotic form) This continuous process affects combustion and engine performance which causing loss of power, excessive fuel consumption, smoking engines, damage to injection systems and carbon soot build up in lube oil, emission filters and catalytic converters.

There are different methods (MPFI, EGR, PCV, catalytic) used which not only gives proper combustion of fuel in engine but also minimize the rate of emission through I.C. engine. One new modern technique to reduce the emission \& gives proper combustion is use of MAGNETIC FUEL CONDITIONER (MFC) $[3,4]$.

\section{MAGNETIC FUEL CONDITIONER (MFC)}

A magnetic fuel conditioner is a device which is used to alter atomic construction and organize fuel molecules (fuel quality) so that proper combustion happens in I.C. engine/automobile. As magnetic field is applied to ionizing fuel feed to combustion chamber which enhance combustion process and gives out lower emission and improved mileage. Magnetic field applied to fuel line atomizes fuel properties which get adheres to more oxygen molecules and enhances fuel air mixture.

This provides peak engine performance while extending engine maintenance and filters change intervals thus reducing harmful emissions and carbon deposits \& also we can ensure more complete combustion. 
Basic concept of magnetize fluid: In 1989, Hans Dehmelt of university of Washington awarded noble prize in physics for his great contribution in fundamental properties of electrons [5]. According to that electrons having ability to store up energy within itself similar to flywheel called spin. When it provides small amount of magnetic field, it absorb the energy and properties will change which is based on the below theories i.e. Chemistry theory - Covalent bond, Physics theory - Barnett effect, Math's theory - Quantum mechanics.

\section{Chemistry theory:}

Particles are made up of number of atoms. In Fig. 1 shows an atom having equals number of Proton \& electron in neutral charge, if greater number of electrons is there then -ve charge is obtained \& if reversed then +ve charge is obtained. We are familiar with construction of fuel molecule (C-- $\mathrm{H}$ bond). Each electron has two movements 1) Spin \& 2) orbital movement which results in mixing of fuels.

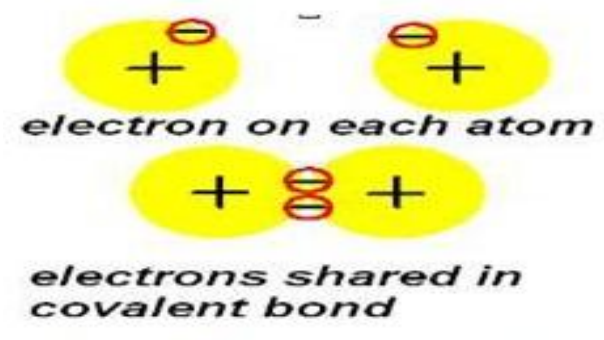

Fig. 1 Basic concept of molecule

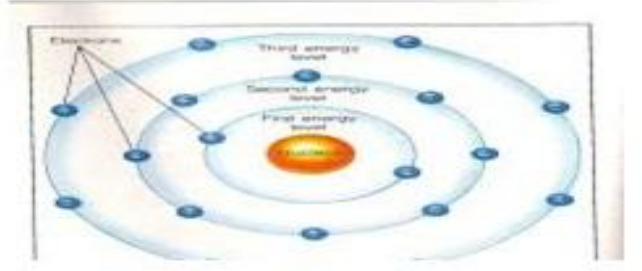

Fig. 2 Molecules showing different energy level

In Fig. 2 shows molecules of fuel has nucleus at it center around which electrons are orbiting, which having tendency to attract towards nucleus, due to which intermolecular force of attraction increases \& thus fuel particle are not actively interlocked with oxygen during combustion \& some un-burn fuel goes into exhaust \& thereby causing incomplete combustion [3,4,5]. When we apply magnetic field around fuel inlet lines, due to magnetization we reduces intermolecular attraction of fuel molecule, which results in better combustion of fuel.

\section{Physics theory:}

Due to Magnetic effect on molecules, spinning electrons will absorb the energy and finally flip into alignment. Because of that cluster structure of fuel breaks i.e. bonds will break into fine particles. Now, this fine particles $(\mathrm{C}$ and $\mathrm{H})$ having magnetic influence, which tend to adhere more oxygen electrons i.e. extra oxidation is done and ultimately complete combustion at its optimum value is obtained, hence pollution will reduced.

\section{Math's theory:}

Quantum (Math's) theory is used for analyzing the above effects which are occurred in covalent bond $\&$ Barnett theory.

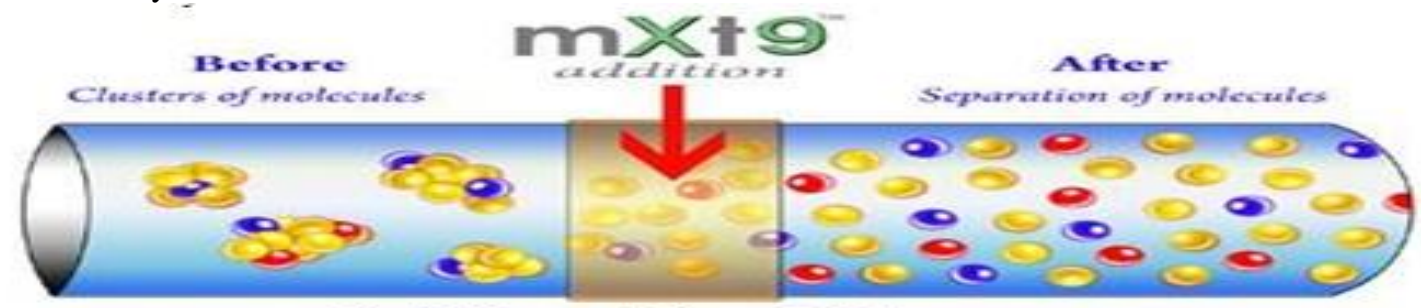

Fig. 3 Schematic View of MFC

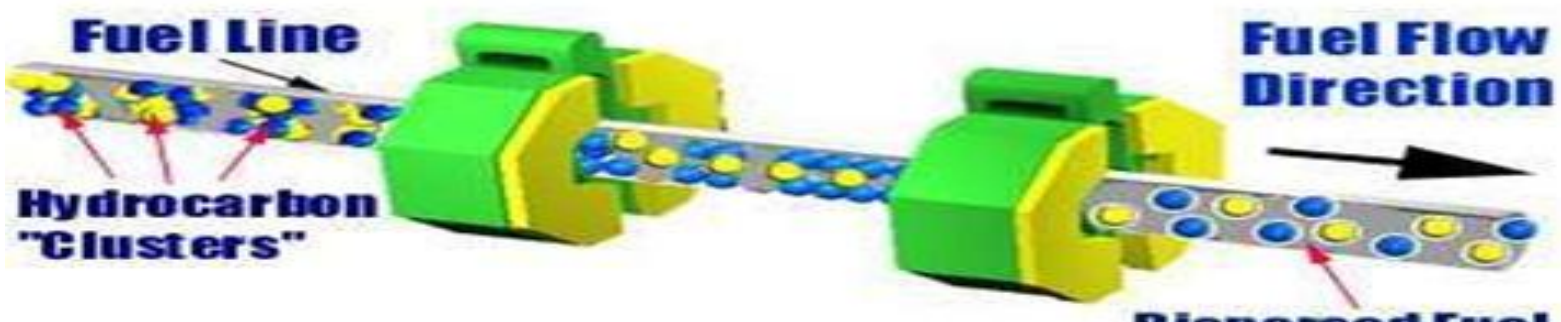

Fig. 4 Mechanism of MFC 


\section{OBJECTIVES OF MFC}

An object of the MFC (Fig.3 \& Fig.4) is to provide significantly improved molecular excitement and turbulence in a petroleum/diesel based fuel so that re-polymerization is more effectively resisted and improved fuel efficiency is achieved. It also significantly achieves improved fuel turbulence so that the premature production of sludge is prevented and the fuel is pumped and burned much more cleanly and successfully. It is particularly effective for improving the combustion efficiency of diesel (due to more repolymerization) fuel. It could be beneficial for use in truck, motor vehicle and marine vessel engines. It is effective for use in virtually all types of internal combustion engines and which is particularly effective for use in high temperature and pressure environments. It achieves a greater molecular turbulence than that of obtained using conventional devices.

\section{PARAMETER OF MFC}

Various parameters which affect the efficiency of fuel combustion are listed below.

\section{Installation Position:}

It is just before the carburetor or injector on inlet pipe or housing for maximum alignment \& maximum effect.

\section{Polarity of magnet:}

Fuel line is magnetized by South Pole and air line is magnetized by North Pole. Such type of opposite polarity burns more completely, producing higher engine output, better fuel economy, and more power and most important reduces the amount of pollutants. The main benefit of sudh opposite polarity dissolves the carbon built up in carburetor jet, spark plug electrode, injector nozzles and combustion chamber help to clean up the engine parts and maintains the clean condition. Therefore the life of engine parts also increases.

\section{Diameter of MFC device:}

Maximum result is being obtained, if diameter is same or close to the system piping.

\section{Length of MFC device:}

It will depend upon the volume of fluid to be treated and intensity of treatment. It is generally varied from 12 to $48 \mathrm{~cm}$.

\section{Magnetic flux:}

Magnetic flux density which is varies differently on flat surface, core surface. It is observed that maximum effect at center.

\section{Selection of permanent magnet:}

The magnet should have a curie temperature sufficiently high that they retained their magnetic characteristic at the operation temperature to which they are exposed. Permanent magnet shows positive result up to its optimum peak, afterwards it will vary.

\section{Magnetic strength:}

The strength of magnet depends on engine size. The magnetic flux density to be imparted to fuel widely varies depending upon fuel, air or stream, combustion equipment \& its condition. In general the preferred range of Magnetic flux density is from 1000-1800 Gauss. Most preferred range for multicylinder is $1400-1800$

Gauss. The field strength is a function of engine size based on fuel consumption. In order to protect magnet from effect of heat generated by engine magnet should provide insulation of aluminium, copper or plastic to block radiant energy a layer of thermal insulation (neoprene) to prevent heating $\&$ radiation. Considering the above parameter few experiments on engine were done which are as follows:

Experimental Methodology (Case Study)

\section{Test Location}

Properties of MFC Device:

The ferrite magnets (Magnetic flux density is from 1000-1800) are most cost effective \& withstand with the temperature of engine inlet line for treating the fuel.

Engine- Single Cylinder, vertical, water cooled self governed diesel engine developing $5 \mathrm{HP}$ at $1500 \mathrm{rpm}$. Brake- Rope brake dynamometer with spring balance \& loading screw. Brake Drum diameter $=0.270 \mathrm{~m}$ 
Belt thickness $=0.006 \mathrm{~m}$ Effective Radius $=0.138 \mathrm{~m}$ For Smoke Meter:

Model name \& Number - NPM-SM-111B Type of Smoke meter - Partial Flow

Display Indication - Light Absorption Coefficient Capacity

Display Range $-0-9.90 / \mathrm{m}$ Scale Resolution $-0.01 / \mathrm{m}$ Linearity $-0.10 / \mathrm{m}$

Warm up time -3 minute

Operating temperature Range $-5-50^{\circ} \mathrm{C}$ Power Required $-230 \mathrm{vAc}$

Weight $-24 \mathrm{~kg}$

Installation done in DIESEL engine

In diesel engine (Fig. 5) we were magnetizing both fuel \& air lines as shown in figure for better effect these magnets are placed nearer to fuel injection pump in diesel engine.

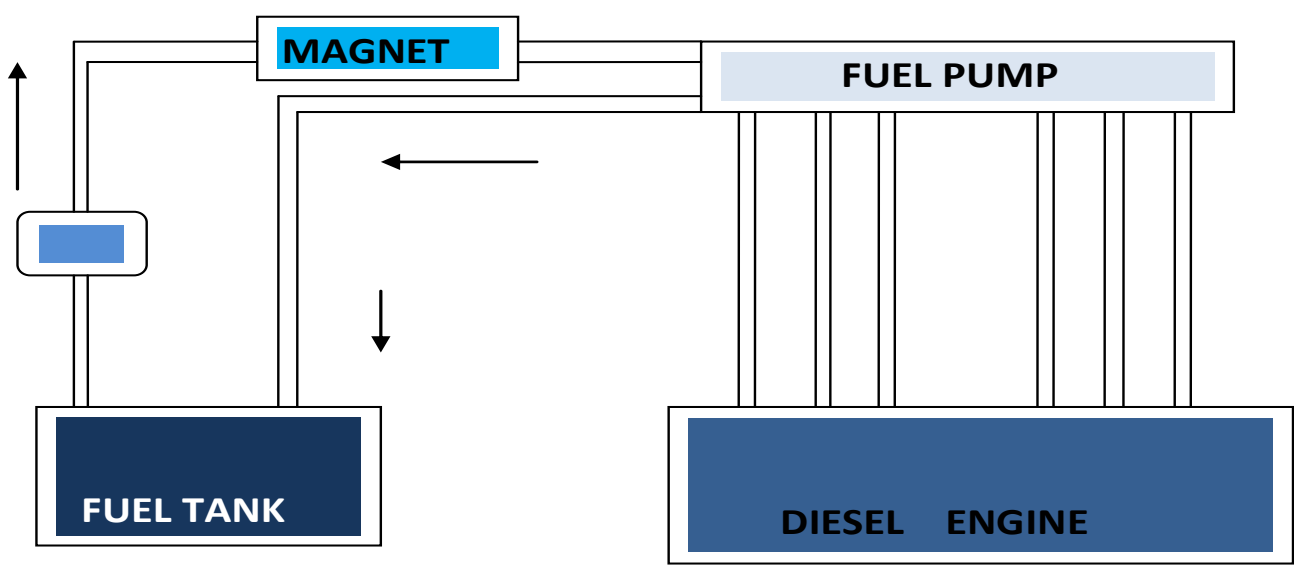

Fig. 5 Installation in DIESEL engine

V TEST AND RESULTS

Trial on single Cylinder Diesel Engine is carried out and results of test are tabulated in

Table 1 Comparison of Diesel with \& without MFC

\begin{tabular}{|c|c|c|c|c|c|c|c|c|c|}
\hline \multirow{2}{*}{ Sr.No. } & \multirow{2}{*}{ Load kg } & \multicolumn{2}{|c|}{$\begin{array}{c}\text { Fuel Consumption } \\
\text { for } \\
10 \mathrm{ml} / \text { second }\end{array}$} & \multicolumn{2}{|c|}{ BSFC Kg/Kuhr } & \multicolumn{2}{|c|}{ Smoke \% } & \multicolumn{2}{|c|}{$\begin{array}{c}\text { Fuel Consumption } \\
\text { Kg/hr }\end{array}$} \\
\cline { 2 - 12 } & & Before & After & Before & After & Before & After & Before & After \\
\hline 1 & 0 & 59 & 88 & 0.0 & 0.0 & 2.5 & 1.03 & 0.475 & 0.31 \\
\hline 2 & 2 & 56 & 64 & 1.11 & 0.97 & 2.43 & 0.94 & 0.5 & 0.44 \\
\hline 3 & 4 & 50 & 56 & 0.63 & 0.5 & 2.41 & 0.92 & 0.56 & 0.5 \\
\hline 4 & 6 & 45 & 49 & 0.46 & 0.43 & 2.04 & 0.99 & 0.62 & 0.57 \\
\hline 5 & 8 & 37 & 52 & 0.43 & 0.31 & 2.24 & 0.79 & 0.76 & 0.54 \\
\hline 6 & 10 & 30 & 47 & 0.42 & 0.27 & 2.24 & 0.79 & 0.95 & 0.59 \\
\hline
\end{tabular}

\section{Performance Evaluation}

The performance of MFC is evaluated by the Fuel Consumption, BSFC value \& Smoke reduction which are shown in Table $1 \&$ also in fig 6, 7. 


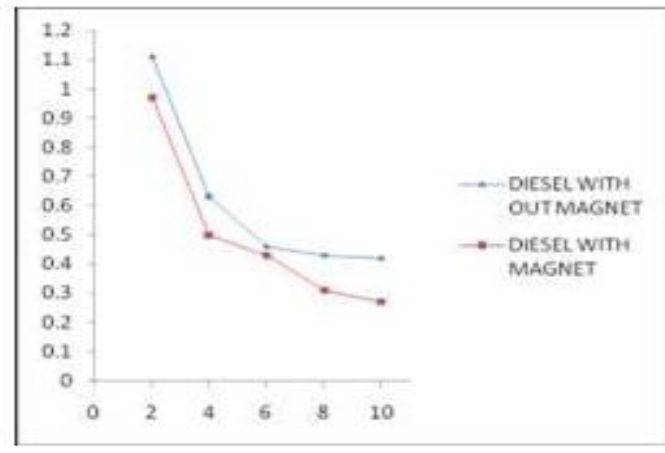

Fig. 6 LOAD (Kg) Vs BSFC (kg/knhkr)

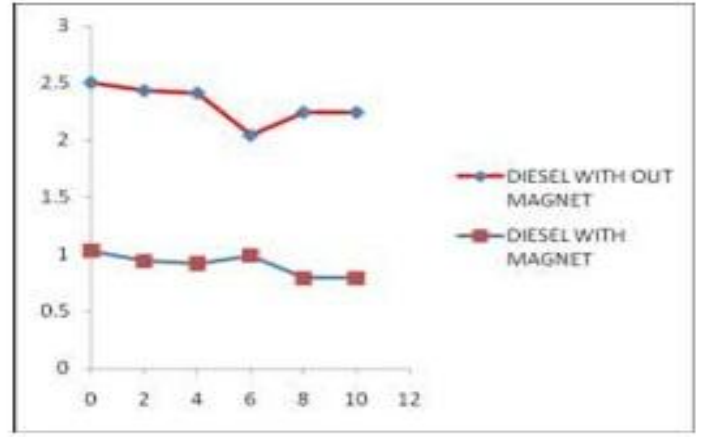

Fig. 7 LOAD (Kg) Vs EXHAUST

\section{APPLICATIONS OF MFC}

MFC has been widely applied in various vehicles such as 2- wheeler, Auto-rickshaw \& Heavy vehicles \& also in aviation for combustion of fuel. It has also been used in various applications other than automobiles. Different types of MFC's are available in market for various applicaions Magnetizer, Fuel Energizer, ALGAE-X, Fuel magic, Power-mag, Fuel-MAX, Max-power, Fuel-Saver-Pro, Mag-tek, Mag-well, Fluid Force \& Fuel conduit etc are being used in Total fuel management system.

Potable water can be safely treated with magnetic. Mag-Tek M.F.C.'s do not introduce any foreign contaminates which would alter the purity. Normal blowdown of the storage tank will reveal a residue of aystal deposits being discharged from the bottom drain. Scheduled blowdown of the hot water storage tank should not be neglected. By monitoring, you will note an increase in temperature of the return hot water line. You will also note a shorter recovery time. This indicates a more efficient heat exchanger. Sectioning a piece of the water line at a remote location will provide a method to visibly inspect the removal rate. Water flow rates will increase at all points in the system.

Mag-Well's Magnetic Fluid Conditioner (MFC) is a proven treatment for removing and preventing the build-up of solid scale and paraffin deposits in oil wells, and is currently being used in over 1,300 wells worldwide.

In addition to the petroleum industry, MagWell MFC has been used for the following applications: the water treatment infrastructure and sugar purification of two sugar refining plants. Imperial Sugar (US) and Kous Sugar Refinery (Egypt); marine diesel fuel treatment for the Coast Guard; gas; bulk ice; and residential and commercial water treatments.

\section{CONCLUSION}

By establishing correct fuel burning parameters through proper magnetic means (MFC) one can assume that an internal combustion engine is getting maximum energy per liter as well as environment with lowest possible level toxic emission. MFC increases the internal energy of a fuel to cause specific changes at a molecular level which obtained easier combustion. The resultant fuel burn more completely, producing higher engine output, better fuel economy, more power \& most importantly reduces the amount of $\mathrm{HC}, \mathrm{CO}, \mathrm{NOx}$ in the exhaust.\& therefore control the emission at low cost. In short the summary of the conclusion includes: MFC increases 10-40\% mileage of vehicle, Reduction in HC emission \& other pollutants, Avoid clogging problems in Diesel Engine, Cost saving, Eco friendly, Provides $30 \%$ extra life for expensive catalytic converter, Reduce maintenance of engine most importantly does not require any design modification \& finally COST SAVING.

\section{REFERENCES}

[1] Busch, K.W., Busch, R.E. and Darling, S. 1976. Design of a test loop for the evaluation water treatment devices. Process safety and environmental protection. Transactions of the Institution of Chemical Engineers.

[2] Tretyakov, I.G., Rybak, M.A. and Stepanenko, E.Yu. 1985. Method of Magnetic Treatment for Liquid Hydrocarbons. In the proceedings of the International Conference on Surface Engineering Application, Washington, USA, 6:80-83.

[3] Marshall, S.V., and Skitek, G.G. 1987. Electromagnetic Concepts and applicationnd Englewood Cliffs, N.J: Prentice-Hall, Inc., New Jersey; 25-150

[4] Janczak Andrew and Krensel Edward. 1992. Permanent magnet more efficient combustion and less pollution. US Pat 5124045; International Class, 027/040; 553402

[5] Masaru Hasegawa, Seiya Mukohara and Yoshihara Achaean. 1988. Influence of Magnetic Field on Kinematic Viscosity of Fuel Oil. In the proceedings of the Eighth International Symposium on Alcohol Fuels, Kobe University of Mercantile Marine, Tokyo, Japan, pp. 77-85.

[6] Kevin Kendall *, Maria R. Kosseva, Nanoparticle aggregation influenced by magnetic fields, Colloids and Surfaces A: Physicochem. Eng. Aspects 286 (2006) 112-116 